\title{
Assessment of Flowering Response in Traditional Rice Varieties of Karnataka to Photo Period
}

\author{
B. Nandini ${ }^{1}$, E. Gangappa ${ }^{2}$, B. Mahesha ${ }^{3}$, M. P. Rajanna ${ }^{4}$, P. Mahadevu ${ }^{4}$, \\ S. Ramesh ${ }^{2}$, Venkatesh ${ }^{1}$ and Shailaja Hittalmani ${ }^{2}$
}

${ }^{1}$ Department of Genetics and Plant Breeding, UAS, Dharwad-580005, India; ${ }^{2}$ Department of Genetics and Plant Breeding, UAS, GKVK, Bengaluru-560065; ${ }^{3}$ ICAR-Indian Institute of Horticultural Research, Hesarghatta Lake Post, Bengaluru-560089; ${ }^{4}$ Zonal Agricultural Research Station, V.C. Farm, Mandya-571405, India

*Corresponding author

\section{A B S T R A C T}

Photoperiod influences several aspects of plant growth. The overall growth and development of plants and flowering are dependent on sunlight. The transition from vegetative to reproductive phase (flowering) is one of the

\section{Keywords}

Flowering response, Traditional rice varieties,

Photo period

Article Info

Accepted:

08 January 2020

Available Online:

10 February 2020 most important decisions a plant has to take in order to guarantee the success of its offspring. Rice is sensitive to photoperiod; hence, a study was undertaken to know the flowering responses of 324 traditional rice varieties (TRV's) of Karnataka to photoperiod, during two distinct season's viz., kharif (2011) and summer (2012) at ZARS V.C Farm Mandya. The results of the study showed that, all the 324 TRV's flowered during kharif with a wide range for $50 \%$ flowering (65 to 124 days). The same set of TRV's after discarding duplicates was raised during summer and the results showed that, 64 TRV's did not flower; 225 flowered with a wide range for days to $50 \%$ flowering ( 71 to 124 days). The study clearly establishes the fact that, flowering in rice cultivars exhibit a wide range of variation in their degree of sensitivity to photoperiod.

\section{Introduction}

Rice is sensitive to photoperiod and exhibits a wide variation in degree of sensitivity to photoperiod. Long-day treatments can prevent or considerably delay its flowering (Wada, 1952). Most of the wild species of
Oryza and many of the primitive cultivated rice (O. sativa $\mathrm{L}$.) are photoperiod sensitive and may be classified as short-day plants. In rice the vegetative growth phase is divided into basic vegetative phase (BVP) and photoperiod-sensitive phase (PSP). The BVP refers to the juvenile growth stage of the 
plant, which is not affected by photoperiod. It is only after the BVP has been completed, then the plant is able to show its response to the photoperiodic stimulus for flowering, which is the PSP of the plant. Optimum photoperiod is the day length at which the duration from sowing to flowering is at a minimum, critical photoperiod is the longest photoperiod at which the plant will flower or the photoperiod beyond which it cannot flower (Vergara and Chang, 1967). Traditional Rice Varieties (TRVs) show very large variation for the duration of their vegetative phase. Long duration TRVs are known to be highly photoperiod sensitive, though for a given TRV, the flowering date remains more or less constant independent of sowing dates (Oka, 1953).

As rice is grown in many tropical and temperate regions, classification of TRVs into photoperiod sensitive and insensitive types is an important breeding objective which enables the breeders to understand their response to photoperiod. Many photoperiod sensitive TRVs are known to carry desirable traits and hence, exploitation of photoperiod sensitivity to optimize heading date and maturity for local environments is very useful. TRVs are known to exhibit a wide range of variation in their degree of sensitivity to photoperiod. This necessitates screening of TRVs for their reaction to photo period. With this premise, a study was undertaken to assess the degree of photoperiod sensitivity among TRVs.

\section{Materials and Methods}

The material for this study consisted of 324 TRVs collected from various parts and maintained at Zonal Agricultural Research Stations (ZARS), Mandya, India. The TRVs were evaluated following 18 x 18 Simple Lattice Design with two replications in two seasons viz., kharif 2011 and summer 2012 at
ZARS, Mandya, India. All the recommended agronomic practices were followed to raise a healthy crop.

For each variety there is a linear relationship between the sowing date and duration of vegetative phase with the slope corresponding to the level of photoperiod sensitivity. An index of photoperiod sensitivity based on the decrease of the duration of the vegetative phase between two sowing dates was computed as below (Clerget, 2007).

$$
\begin{aligned}
& \text { Degree of photoperiod } \\
& \text { sensitivity }(K p)
\end{aligned}=\frac{\text { Dur1 }- \text { Dur2 }}{\text { DatS2 }- \text { DatS1 }}
$$

Where,

1. Dur1 and Dur2 are the durations in days from sowing to heading for the first and second sowing dates, respectively

2. DatS1 and DatS2 are the first and second sowing dates in Julian days

$K p$ measure the degree of photoperiod sensitivity and is expected to vary from 0.00 to 1.00. ' 0.00 ' refers for photoperiod insensitive TRVs (No change in the duration of their vegetative phase with the sowing dates) and 1.00 refers for most strongly photoperiod sensitive TRVs (Show variation in the duration of their vegetative phase, which change with their vegetative phase to the same extent as the delay in sowing, keeping the calendar date of flowering constant).

\section{Results and Discussion}

During kharif (2011) season, the first flowering by an entry was recorded on $3^{\text {rd }}$ October and the last entry to flower was on $28^{\text {th }}$ November, indicating that the flowering period was spread over 57 days among the TRVs. Similarly, during summer flowering 
period by the TRVs was spread across 54 days ( $5^{\text {th }}$ April to $28^{\text {th }}$ May). Based on this data the degree of photo period sensitivity was estimated (Table 1 and 2) and is depicted in Figure 1a-1b.

It is evident from the data that, variation was noticed among the TRVs for the degree of photoperiod sensitivity $(K p)$ that ranged from zero to 0.4. As many as $18 \mathrm{TRVs}$ showed zero $K p$ value such as Gowrisanna, K.N. local, Bangara Kaddi and etc. Sanna mallige and Laalya showed 0.41 and $0.36 K p$ value, respectively.

It is clearly evident that the TRVs belonging to very early/early flowering group exhibited a $K p$ value near to 0 . The TRVs which recorded $K p$ value of more than $>0.3$ were late to flower, with low to medium spikelet fertility, and low tillering ability (Table 2). This establishes an association between number of days taken to flowering and photo period sensitivity as measured $K p$ value. Further, the degree of photo sensitivity appeared linear to degree of late flowering among TRVs.

Table.1 Top 15 photoperiod insensitive TRVs with their degree of photoperiod sensitivity ( $K p$ ) and related yield traits

\begin{tabular}{|l|l|l|l|l|l|l|l|l|l|l|l|}
\hline Sl. No & TRVs & Kp & DFF & PHT & PL & PT & SF & SW & SY & HI & S.Yld \\
\hline $\mathbf{1}$ & Gowrisanna & 0.00 & 115.75 & 119.48 & 22.19 & 8.94 & 76.69 & 16.86 & 18.49 & 0.43 & 13.65 \\
\hline $\mathbf{2}$ & K.N. local & 0.00 & 85.00 & 117.50 & 23.45 & 13.88 & 76.23 & 19.88 & 24.39 & 0.53 & 17.36 \\
\hline $\mathbf{3}$ & Mugad Sugandha & 0.00 & 93.25 & 89.90 & 22.50 & 10.13 & 79.88 & 20.55 & 18.74 & 0.48 & 17.65 \\
\hline $\mathbf{4}$ & Bangara Kaddi & 0.00 & 88.25 & 110.06 & 21.60 & 9.94 & 76.62 & 22.31 & 17.26 & 0.45 & 13.32 \\
\hline $\mathbf{5}$ & Dodda alur & 0.00 & 78.25 & 121.49 & 22.55 & 9.29 & 65.67 & 29.00 & 17.87 & 0.47 & 15.57 \\
\hline $\mathbf{6}$ & Jeervel & 0.00 & 74.25 & 102.49 & 21.50 & 7.96 & 76.80 & 20.68 & 15.25 & 0.46 & 12.98 \\
\hline $\mathbf{7}$ & Jig madike & 0.00 & 87.75 & 116.15 & 21.90 & 8.96 & 79.28 & 20.53 & 17.34 & 0.52 & 17.77 \\
\hline $\mathbf{8}$ & Onamardani nellu & 0.00 & 84.25 & 124.79 & 22.65 & 10.59 & 77.97 & 25.37 & 17.26 & 0.49 & 16.67 \\
\hline $\mathbf{9}$ & Adikane & 0.00 & 85.75 & 105.05 & 23.00 & 7.20 & 86.56 & 23.30 & 14.72 & 0.51 & 15.35 \\
\hline $\mathbf{1 0}$ & Babbayam & 0.00 & 98.25 & 105.24 & 22.35 & 7.73 & 83.24 & 25.15 & 11.04 & 0.54 & 13.00 \\
\hline $\mathbf{1 1}$ & Bilirajamudi & 0.00 & 81.25 & 136.34 & 24.65 & 6.21 & 77.53 & 28.08 & 15.20 & 0.49 & 13.79 \\
\hline $\mathbf{1 2}$ & Karidoodi & 0.00 & 89.75 & 129.61 & 23.70 & 7.96 & 77.94 & 21.16 & 17.30 & 0.40 & 10.81 \\
\hline $\mathbf{1 3}$ & Malgudi sanna & 0.00 & 85.25 & 127.45 & 24.80 & 9.54 & 81.97 & 20.34 & 23.17 & 0.45 & 18.25 \\
\hline $\mathbf{1 4}$ & Mullu batta & 0.00 & 88.00 & 124.18 & 23.70 & 8.13 & 82.16 & 21.08 & 13.05 & 0.51 & 14.04 \\
\hline $\mathbf{1 5}$ & Possugandhi & 0.00 & 85.25 & 124.95 & 22.00 & 8.15 & 74.73 & 23.40 & 14.76 & 0.57 & 19.57 \\
\hline DFF & -Days to 50\% flowering & SW & -1000 & seed weight (g) & PT & -Productive tillers plant ${ }^{-1}$ \\
\hline PHT & -Plant height (cm) & & SY & - Straw yield plant & SF & - Spikelet fertility $(\%)$ \\
\hline PL & -Panicle length (cm) & & HI & - -Harvest index & S.YLD & - Single plant yield(g) \\
\hline
\end{tabular}


Table.2 Top 15 photoperiod sensitive TRVs with their degree of photoperiod sensitivity $(K p)$ and related yield trait

\begin{tabular}{|l|l|l|l|l|l|l|l|l|l|l|l|}
\hline SI. No & TRVs & $\boldsymbol{K} \boldsymbol{D}$ & DFF & PHT & PL & PT & SF & SW & SY & HI & S.Yld \\
\hline $\mathbf{1}$ & Gandha Sale & 0.21 & 100.00 & 116.99 & 23.30 & 8.54 & 73.87 & 15.55 & 12.03 & 0.49 & 11.40 \\
\hline $\mathbf{2}$ & Kalajeera & 0.21 & 94.00 & 121.75 & 24.05 & 14.98 & 82.70 & 21.46 & 18.03 & 0.36 & 8.20 \\
\hline $\mathbf{3}$ & Kali katesi & 0.21 & 98.75 & 110.14 & 20.15 & 9.45 & 61.18 & 20.20 & 13.40 & 0.33 & 6.94 \\
\hline $\mathbf{4}$ & Andra basumati & 0.21 & 99.75 & 114.10 & 22.55 & 6.25 & 80.45 & 29.65 & 15.33 & 0.50 & 15.72 \\
\hline $\mathbf{5}$ & Tiruvani & 0.21 & 99.00 & 127.11 & 22.95 & 7.98 & 69.66 & 30.25 & 12.11 & 0.53 & 14.66 \\
\hline $\mathbf{6}$ & Dangi Red & 0.22 & 93.00 & 106.68 & 20.30 & 10.11 & 75.70 & 22.57 & 16.23 & 0.37 & 9.81 \\
\hline $\mathbf{7}$ & Alubulla & 0.22 & 102.75 & 121.45 & 24.45 & 7.45 & 76.78 & 18.62 & 14.32 & 0.56 & 15.65 \\
\hline $\mathbf{8}$ & $\begin{array}{l}\text { Dappaneya } \\
\text { belejaddu }\end{array}$ & 0.22 & 98.50 & 134.71 & 24.00 & 7.99 & 82.76 & 27.83 & 16.15 & 0.45 & 12.71 \\
\hline $\mathbf{9}$ & Danggia & 0.23 & 99.75 & 131.21 & 22.15 & 9.04 & 79.13 & 20.24 & 14.47 & 0.40 & 10.44 \\
\hline $\mathbf{1 0}$ & Neermulka & 0.23 & 103.25 & 118.39 & 24.45 & 10.79 & 77.89 & 22.95 & 18.13 & 0.46 & 14.62 \\
\hline $\mathbf{1 1}$ & Kulaj & 0.24 & 96.00 & 121.08 & 22.75 & 12.58 & 75.52 & 22.08 & 13.46 & 0.45 & 10.49 \\
\hline $\mathbf{1 2}$ & Tulasiya & 0.24 & 94.75 & 119.41 & 21.70 & 7.51 & 82.68 & 20.21 & 11.35 & 0.53 & 12.63 \\
\hline $\mathbf{1 3}$ & Akkalu & 0.25 & 99.75 & 119.16 & 23.10 & 6.95 & 79.11 & 28.69 & 13.97 & 0.51 & 13.95 \\
\hline $\mathbf{1 4}$ & Laalya & 0.36 & 97.00 & 120.74 & 23.95 & 11.54 & 81.88 & 20.23 & 13.17 & 0.44 & 10.54 \\
\hline $\mathbf{1 5}$ & Sanna mallige & 0.41 & 97.50 & 103.53 & 24.55 & 8.10 & 78.24 & 27.71 & 9.37 & 0.60 & 14.12 \\
\hline DFF & -Days to 50\% flowering & SW & -1000 seed weight (g) & PT & -Productive & tillers \\
& & & & & & & & plant & & & \\
\hline PHT & -Plant height (cm) & & SY & -Straw yield plant & & & SF & -Spikelet fertility (\%) \\
\hline PL & -Panicle length (cm) & & HI & -Harvest index & & S.YLD & -Single plant yield(g) \\
\hline
\end{tabular}

Figure.1a Degree of photo period sensitivity in TRVs

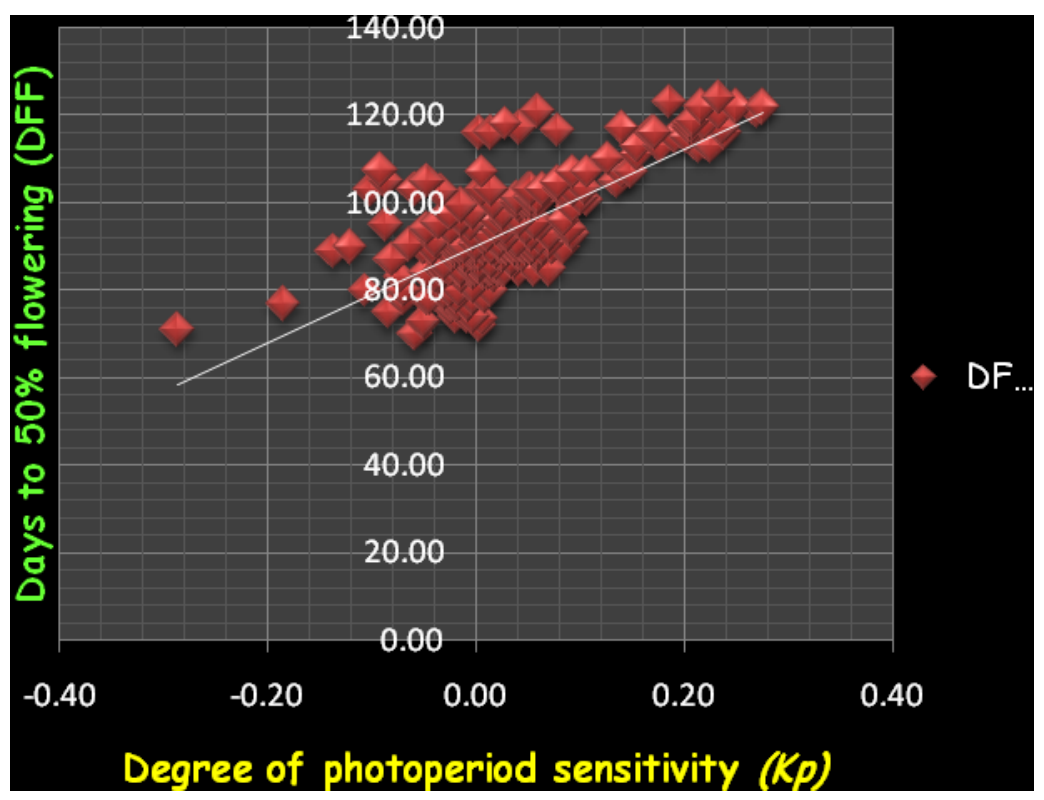




\section{Figure.1b Number of TRVs exhibiting degree of photo period sensitivity}

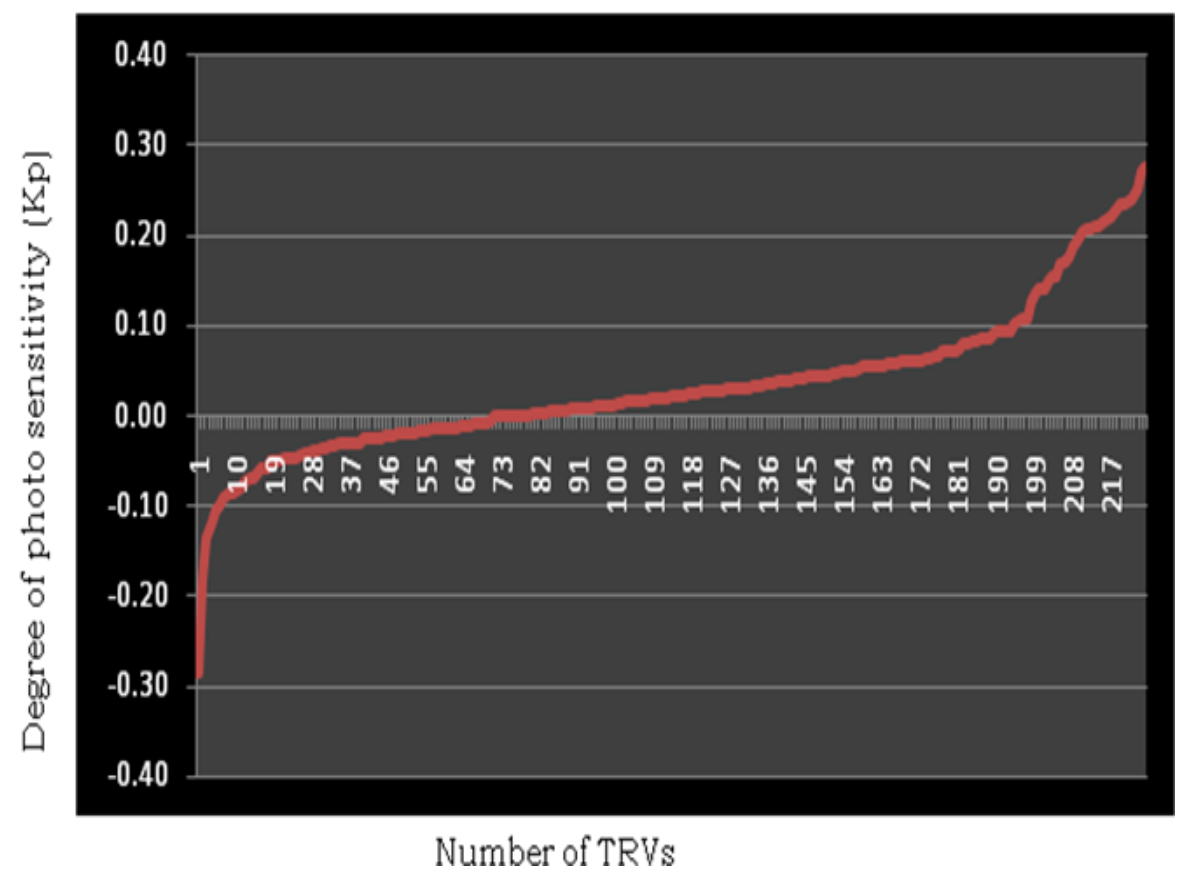

Photoperiod insensitive TRVs are early to flower with high spikelet fertility when compared to photoperiod sensitive TRVs (Table 1). Similarly straw yield plant $^{-1}$ was high along with yielding ability of photoperiod insensitive TRVs were relatively higher than the photoperiod sensitive once. It may be due to the photoperiod insensitive TRVs are constant with respect to day length required for flowering in comparison with photoperiod insensitive once.

Photoperiod response of the rice plant is governed by the length of the longest continuous dark hour. Very short light hours during the dark period may markedly affect the time of flowering in some cultivars. The important practical utilization of this observation is that it provides immediate information and exact estimation of degree of sensitivity in TRVs by comparing the single date of sowing and its vegetative phase.

\section{References}

Clerget, B., Rattunde, H. F. W., Dagnoko, S and Chantereau, J., 2007. An easy way to assess photoperiod sensitivity in sorghum: Relationships of the vegetative-phase duration and photoperiod sensitivity. e J. ICRISAT. Org 3(1): 1-4.

Oka, H. I., 1953. Varietal variation of the response to day length and temperature and the number of days of growing period. Jap. J. Breed. 4: 92-100.

Vergara, B. S., Chang, T. T. and Li. C. C. 1967. Components of growth duration and their inheritance. Proc. Rice Tech. Working Group, 1966:17-18.

Wada, E. 1952. Studies on the response of heading to daylength and temperature in rice plants. I. Response of varieties and the relation to their geographical distribution in Japan [translation]. Jpn. J. Breed. 2:55-62. 


\section{How to cite this article:}

Nandini, B., E. Gangappa, B. Mahesha, M. P. Rajanna, P. Mahadevu, S. Ramesh, Venkatesh and Shailaja Hittalmani. 2020. Assessment of Flowering Response in Traditional Rice Varieties of Karnataka to Photo Period. Int.J.Curr.Microbiol.App.Sci. 9(02): 1224-1229. doi: https://doi.org/10.20546/ijcmas.2020.902.145 